\title{
REVITALISASI PENGELOLAAN ASRAMA DALAM MENGEMBANGKAN PENDIDIKAN BAGI SUKU DAYAK DI WILAYAH PERBATASAN KABUPATEN SANGGAU
}

\author{
Suko $^{1}$, Felisitas Yuswanto ${ }^{2}$ \\ Sekolah Tinggi Agama Katolik Negeri Pontianak, Email :Sukotaonarab@gmail.com \\ Sekolah Tinggi Agama Katolik Negeri Pontianak, email :joezzwwn@yahoo.com
}

\begin{tabular}{l}
\hline Riwayat Artikel \\
\hline Dikirim : 12 Oktober 2020 \\
Direvisi : 23 Desember 2020 \\
Diterima: 3 Januari 2021
\end{tabular}

\begin{abstract}
Abstrak
Sekolah berfasilitas asrama mengkombinasikan tempat tinggal para peserta didik di Institusi Sekolah yang jauh dari rumah dan keluarga, diajarkan agama serta pembelajaran beberapa mata pelajaran sesuai kurikulum pendidikan. Artikel ini bertujuan untuk mendeskrifsikan pembahasan tentang kuantitas dan kualitas peserta didik Suku Dayak yang tinggal di asrama saat ini, menemukan faktor penyebab kurangnya minat anak untuk tinggal di asrama, dan keterlibatan Gereja Katolik dalam merevitalisasi asrama dalam mengembangkan pendidikan bagi suku Dayak di Wilayah Perbatasan Keuskupan Sanggau. Metode yang digunakan ialah kualitatif dengan sumber data pengelola asrama, anak asrama putra/putri dan anak yang tidak tinggal di asrama. Data diperoleh dari hasil observasi, wawancara, dan dokumenter. Data dianalisis secara kualitatif. Hasil penelitian ditemukan bahwa kualitas dan kuantitas anak yang mau tinggal di asrama sangat berkurang. Hal tersebut disebabkan oleh sekolah Katolik yang memiliki fasilitas asrama bersaing semakin ketat dengan yayasan pendidikan lain, kurang terjaminnya fasilitas sekolah dan asrama, tata tertib asrama yang lemah, banyaknya tawaran tempat tinggal (kost-kostan) atau tempat orang tua/saudara yang terjangkau dari lokasi sekolah, biaya sekolah Katolik yang memiliki fasilitas asrama relatif dianggap mahal, dan karakter peserta didik yang tidak suka terikat pada aturan yang dianggap membebani.
\end{abstract}

Kata kunci: Revitalisasi Asrama, Pendidikan bagi suku Dayak

\begin{abstract}
Abtract
Boarding schools combine the residences of students in school institutions away from home and family, religiously taught and taught several subjects according to the educational curriculum. This article aims to de-describe the discussion about the quantity and quality of Dayak students living in dormitories today, find the factors that cause the lack of interest of children to live in dormitories, and the Involvement of the Catholic Church in revitalizing dormitories in developing education for dayak tribes in the Border Region of the Diocese of Sanggau. The method used is qualitative with data sources of dormitory managers, dormitory children sons / daughters and children who do not live in dormitories. Data obtained from observations, interviews, and documentaries. Data is analyzed qualitatively. The results of the study found that the quality and quantity of children who want to live in dormitories is greatly reduced. This is because Catholic schools that have dormitory facilities compete more closely with other educational foundations, lack of guaranteed school and dormitory facilities, weak dormitory discipline, the number of housing offers (boarding schools) or affordable parents/relatives from the school location, catholic school fees that have dormitory facilities are relatively expensive, and the character of students who do not like to be bound by rules that are considered burdensome.
\end{abstract}

Key words: Revitalization of Dormitories, Education for Dayak people

\section{PENDAHULUAN}

Revitalisasi menempuh pendidikan di kota atau daerah lain. Pendidikan yang berkarakter asrama dapat mempertahankan nilai-nilai moral dan mengembangkan karakter, beriman, semangat kekelurgaan, gotong-royong, disipilin yang berlandasakan cinta kasih Kristus sebagai tujuan meningkatkan dunia pendidikan (KWI, 1991). Perkembangan sejarah Gereja Katolik di 
Kalimantan Barat berperan penting dalam dunia pendidikan bagi Suku Dayak. Bahkan sebelum kemerdekaan pendidikan sekolah Katolik sudah dirintis oleh para misionaris di daerah pedalaman Kalimantan (Wikipedia, n.d.-a). Ciri khas Gereja Katolik yang dibawa oleh para misionaris sangat kental dengan nuansa pendidikan Katolik yang berfasilitas asrama (Winata, n.d.). Perhatian besar Gereja pada bidang pendidikan meyakini bahwa pendidikan mempunyai makna sangat penting dalam kehidupan dalam mengembangkan pengetahuan, keagamaan, sosial, kemasyarakatan, politik, ekonomi, teknologi, dan sebagainya (Susiyani, n.d.).

Sekolah berasrama adalah lembaga pendidikan dimana para siswa tidak hanya belajar, tetapi mereka bertempat tinggal dan hidup menyatu di lembaga tersebut. Sekolah berasrama mengkombinasikan tempat tinggal para siswa di Institusi Sekolah yang jauh dari rumah dan keluarga mereka dengan diajarkan agama serta pembelajaran beberapa mata pelajaran sesuai kurikulum pendidikan (Suci, 2017).

Persekolahan yang memiliki asrama membantu bangsa Indonesia yang sedang menggalakan konsep pendidikan berbasis karater, maka asrama menjadi salah satu cara yang tepat (Sholikhun, 2018). Gereja mendirikan sekolah yang dilengkapi dengan fasilitas asrama mempermudah dalam pembentukan karakter, menyediakan tempat tinggal bagi putra/putri Suku Dayak yang berkeinginan untuk sekolah dengan jarak tempuh yang jauh.

Konsep pendidikan sekolah Katolik yang dilengkapi dengan fasilitas asrama memungkinkan usaha Gereja mewartakan dan mencari kebenaran serta mengembangkan cinta kasih (R. Hardawiryana (Trj.), 2002). Gereja mendukung dan meyakini pendidikan berbasis asrama dapat meningkatkan kualitas dalam bidang pendidikan serta menolong orang-orang agar dapat mencapai kepenuhan Kristiani (KWI, 1991). Oleh karena itu, Anak-anak yang dididik dalam sekolah yang memiliki fasilitas asrama tidak hanya memiliki intelektual tinggi, tapi juga memiliki toleransi, karakter, dan moral yang kuat (Abisada Warstef, 2013). Dalam pengembangan aspek intelektual siswa mengikuti kegiatan belajar-mengajar regular atau formal di sekolah berdasarkan kurikulum nasional. Sedangkan pembentukan moral dan karakter lebih banyak dilakukan di asrama (Faridah et al., 2018).

De facto, keterlibatan Gereja Katolik wilayah Kalimantan Barat dalam dunia pendidikan sudah cukup lama. Sejarah mencatat bahwa Persekolahan Katolik Nayarumkop (PKN) merupakan persekolahan Katolik swasta pertama yang dilengkapi dengan fasilitas asrama. Perjalanan waktu yang panjang keterlibatan Gereja yakni, Keuskupan yang ada di wilayah Kalimantan Barat ambil bagian dalam mengembangkan dunia pendidikan dengan mendirikan sekolah yang menyediakan fasilitas asrama (Wikipedia, n.d.-b). Secara khusus Keuskupan Sanggau yang berdekatan dengan wilayah perbatasan juga terlibat dalam bidang pengelolaan sekolah yang dilengkapi dengan fasilitas asrama.

Persekolahan Katolik dengan fasilitas asrama, bahkan sudah menghasilkan lulusan yang berkualitas dan alumi yang berkarya di berbagai bidang profesi dalam dan Luar Negeri (Naili et al., n.d.) Hal ini menunjukkan bahwa pendidikan atau sekolah Katolik swasta yang memiliki fasilitas asrama dapat menjadi contoh dalam mengembangkan dunia pendidikan bagi peserta didik Suku Dayak di wilayah perbatasan (www.atmajaya.ac.id, n.d.).

Salah satu faktor pendukung berkembangnya pendidikan bagi Suku Dayak adalah adanya fasilitas sekolah Katolik yang memiliki asrama. Sekolah Katolik berfasilitas asrama menjadi cara untuk menempuh pendidikan dan solusi bagi orang tua untuk menyekolahkan anaknya. Orang tua menyekolahkan anak di sekolah berasrama dengan pertimbangan memiliki waktu belajar yang lebih panjang dan lebih fokus, memungkinkan anak untuk lebih mandiri dan lebih siap dalam mempersiapkan berbagai macam tantangan yang akan dihadapinya dimasa yang akan datang (Naili et al., n.d.). Orang tua meyakini bahwa Gereja (biarawanbiarawati) bertugas memdidik, membina iman anak untuk memiliki sikap toleransi, karakter, kebersamaan, etika, disiplin, mandiri, dan moral yang kuat (KWI, 1991).

Perkembangan zaman, kemajuan teknologi dan gaya hidup dalam berbagai bidang kehidupan sudah mulai menggeser kualitas, kuantitas, dan pola persekolahan Katolik Swasta yang memiliki fasilitas asrama sudah dianggap lama dan konvensional menuju pola baru yang dianggap moderat (Widyastuti, n.d.). Oleh karena itu, quo vadis persekolahan Katolik yang memiliki fasilitas asrama dalam mengembangkan pendidikan bagi Suku Dayak? Dahulu asrama menjadi pilihan utama tempat tinggal bagi putra/putri Suku Dayak di pedalaman selama menempuh pendidikan. Kini Persekolahan Katolik yang memiliki fasilitas asrama sebagai bentuk yang digunakan oleh Gereja untuk membantu anak Suku Dayak pedalaman agar dapat mengembangkan pendidikan mulai memudar. Persekolahan Katolik yang berfasilitas asrama mulai redup. Sekarang asrama bukan mejadi tempat favorit 
sebagai tempat tinggal selama proses pendidikan berlangsung. Namun persekolahan Katolik yang memiliki fasilitas asrama dianggap sebagai pembatas dalam mengembangkan diri. Asrama menjadi momok yang menganut dengan sederetan peraturan dan larangan yang membatasi diri dalam perkembangan pribadi, serta sekolah dari asrama dianggap mahal. Saat ini sekolah Katolik yang memiliki fasilitas asrama bukan tempat tinggal yang utama dalam proses perkembangan pendidikan oleh segelitir orang termasuk didalamnya putra-putri Suku Dayak.

Proses revitalisasi pendidikan atau sekolah Katolik berfasilitas asrama dalam mengembangkan pendidikan bagi suku Dayak mencakup perbaikan aspek budaya, aspek fisik, aspek ekonomi dan aspek sosial. Oleh karena itu, pendekatan revitalisasi mampu mengenali dan memanfaatkan potensi lingkungan budaya setempat.

Nilai-nilai sekolah Katolik berfasilitas asrama sepintas dapat kita temukan dalam dokumen Gereja Katolik yang menekankan pentingnya semangat kekeluargaan dan persaudaraan dibangun di lembagalembaga Pendidikan Katolik (Nugroho, n.d.). Oleh sebab itu, Gereja mengharapkan agar semangat persaudaraan menjadi salah satu ciri khas Sekolah Katolik. Perbedaan sekolah Katolik dengan sekolah lain menjadi tugas khas lembaga pendidikan Katolik untuk mewujudkan suasana kekeluargaan di sekolah yang dijiwai oleh semangat kebebasan dan cinta kasih Injil.

Pendidikan berfasilitas asrama juga mengarah pada paham Konsili Suci yang menyatakan bahwa anakanak dan kaum remaja berhak didukung untuk belajar menghargai dengan suara hati yang lurus mengandung nilai-nilai moral, serta dengan tulus menghayatinya secara pribadi, untuk makin sempurna mengenal serta mengasihi Allah (R. Hardawiryana (Trj.), 2002).

Sekolah berfasilitas asrama menanamkan nilai kedisiplinan berkat pengasuhan atau bimbingan dari para Pastor/Bruder atau Suster asramanya. Selain itu, ada aturan-aturan yang apabila ditaati bukan saja akan membentuk karakter yang baik bagi anak-anak, tetapi juga akan membantu anak-anak agar dapat belajar dan hidup lebih teratur, baik, disiplin, dan bertanggung jawab. Anakanak di asrama akan menjadi lebih sadar bahwa tugas utamanya sebagai pelajar adalah untuk belajar (Purnadi, 2015).

Hakikat kehidupan asrama bukan sekedar pembentukan kebiasaan, namun juga suatu proses pembentukan nilai-nilai hidup. Kehadiran sekolah berfasilitas asrama memberikan alternatif pendidikan yang terbebas dari polusi sosial yang melanda lingkungan kehidupan masyarakat seperti pergaulan bebas, narkoba, perkelahian antar pelajar, dan lain-lain (Maslihah, 2011). Sekolah berasrama memiliki kesempatan merancang program pendidikan yang komprehensif dan holistik dari program pendidikan keagamaan, life skill, soft skill, dan hard skill. Pendampingan kepada peserta didik dilakukan secara personal sesuai dengan bakat dan minat masingmasing. Pendamping asrama memfasilitasi proses berkembang peserta didik sebagai kekhasan masingmasing pribadi. Asrama memungkinkan peserta didik berkembang menjadi manusia yang berkontribusi besar bagi kemanusiaan. Peserta didik dilatih berinteraksi dengan orang lain yang beragam sekaligus menjadi wahana untuk mengasah kerjasama, menghargai perbedaan, saling bantu membantu dan tolong-menolong satu sama lain (Nugroho, n.d.).

\section{METODE}

Penelitian ini menggunakan metode deskriptif kualitatif (Dewantara et al., 2020) dengan melakukan observasi, wawancara, dan dokumentasi lapangan. Metode kualitatif digunakan dengan tujuan agar mendalami lebih dalam permasalahan, fenomena-fenomena yang terjadi berkaitan dengan revitalisasi pengelolaan asrama dalam mengembangkan pendidikan bagi Suku Dayak di wilayah perbatasan Kabupaten Sanggau Kalimantan Barat. Penelitian bersifat deskriptif kualitatif karena data yang diperoleh melalui suatu langkah kerja dengan konsep yang beragam.

Teknik analisis data dilakukan secara deskriptif kualitatif dengan melakukan pemeriksaan keabsahan data. Pengolahan data dengan memilah-milah data, kemudian dilakukan pengelompokan sesuai data yang dikumpulkan berdasarkan masalah-masalah yang ditemukan. Melakukan pemeriksan kembali terhadap data yang ditemukan sampai analisis terakhir untuk menyimpulkan hasil penelitian dan temuan. Analisis data tampak pada tahap-tahap dilakukannya sebuah penelitian dengan analisis masalah penelitannya. Kekahasan penelitian kualitatif mampu menganalisa data selama penelitian berlangsung. Lalu melakukan analisis terhadap catatan lapangan yang ditemukan dalam penelitian. Menindaklanjuti hasil temuan awal yang dilakukan oleh tim penelitian. Langkah selanjutnya tim penelitian melakukan obervasi, wawancara, dan dokumentasi kembali sebagai tindaklanjut dari temuan awal. Upaya tersebut untuk mendalami data. Tahap berikutnya para peneliti memperdalam data dengan melakukan langkah strategi penelitian berikutnya dalam memperoleh data 
dengan mengobservasi dan mewawancarai kembali sumber data di hari yang berbeda sampai data jenuh. Pada tahap analisis data lajutan terhadap hasil penelitian yang sudah dilakukan dari lapangan, tim penelitian membuat laporan akhir yang berisikan seluruh proses hasil penelitian sampai pada kesimpulan akhir (Putra, 2011).

\section{HASIL DAN PEMBAHASAN}

Berdasarkan hasil penelitian yang sudah dianalisa secara kulitatif menunjukkan kuantitas anak Suku Dayak yang tinggal di asrama selama menempuh pendidikan berdasarkan hasil wawancara saat ini mengalami penurunan dari tahun ke tahun. Pada hal dahulu ketika orang Dayak sekolah lebih memilih pendidikan di sekolah Katolik yang memiliki fasilitas asrama dalam mengembangkan pendidikan di wilayah perbatasan Keuskupan Sanggau Kalimantan Barat. Perkembangan jaman mulai mengikis konsep menenmpuh pendidikan dengan tinggal di asrama, seperti terbukanya akses tansportasi, teknologi dan informasi turut mengikis model pendidikan yang memiliki asrama sebagai tempat tinggal selama sekolah. Seperti penuturan seorang pembina asrama putra di wilayah perbatasan; pada saat ini terjadi penurunan jumalah anak yang mau tinggal di asrama selama menempuh pendidikan. Saat ini anak yang masih tinggal di asrama beranggotakan rata-rata delapan puluhan orang anak. Bila dibandingkan dengan jaman terdahulu anak yang tinggal di asrama berjumlah 200-300 orang. Kurun waktu 1 tahun terakhir terjadi pengurangan anak yang tinggal di asrama. Awal tahun ajaran anak yang tinggal di asrama mencapai 100 orang namun yang bertahan sampai akhir menjadi delapan puluhan orang.

Demikian juga dengan asrama putri, dilihat dari kuantitas siswi yang mau tinggal di asrama dalam penuturan Suster sebagi Pembina asrama juga mengalami penurunan. Penurunan penghuni asrama dari tahun ketahun terus terjadi. Dahulu anak purti yang tinggal di asrama rata-rata 100-200 orang namun sekarang paling banyak tujuh puluhan orang.

Lain halnya dengan penuturan pembina asrama dilokasi yang berbeda. Kuantitas anak yang tinggal di asrama putri cukup tinggi, bahkan kamar asrama yang disediakan mengalami kekurangan. Minat anak putri yang masuk asrama sebagai tempat tinggal selama menempuh pendidikan di SMP/SMA cukup tinggi. Sementara fasilitas asrama untuk putra tidak tersedia.

Kemudian kuantitas penghuni asrama di wilayah Sekayam dan Entikong juga menegaskan perkembangan jumlah anak asrama dari tahun ketahun mengalami penurunan. Untuk saat ini jumlah anak asrama ada 34 orang. Bila dibandingkan dengan tahun sebelumnya jumlah anak asrama bisa mencapai 50-100 orang. Dari jumlah yang ada tersebut mengalami penurunan secara terus menerus dengan adanya seleksi alam yang pada akhirnya membuat mereka keluar dari asrama sebagai tempat tinggal.

Berdasarkan hasil penelitian dari sisi kualitas anak yang tinggal di asrama selama menempuh pendidikan di sekolah tetap menjadi anak yang unggul dalam berbagai bidang, seperti prestasi dan kepribadian. Oleh karena itu, pengelolaan asrama sebagai fasilitas dalam mengembagkan pendidikan bagi Suku Dayak di wilayah perbatasan Keuskupan Sanggau Kalimantan Barat tetap menekankan kualitas dari anak-anak yang tinggal di asrama selama menempuh pendidikan. Sampai saat ini de facto dari penuturan pembina asrama menyatakan kualitas anak yang tinggal di asrama secara akademis lebih tinggi dari anak yang tinggal dengan orang tua/kos. Pengelolaan oleh pembina asrama sangat menanamkan kualitas dari nilai kedisiplinan yang ada asrama. Bahkan aturan-aturan yang apabila ditaati bukan saja akan membentuk karakter yang baik bagi anak-anak, tetapi juga membantu anak untuk belajar, hidup lebih teratur, baik, disiplin, dan bertanggung jawab. Pengelolaan asrama yang demikian mengantar anak-anak di asrama akan menjadi lebih sadar bahwa tugas utamanya sebagai pelajar adalah untuk belajar secara pengetahuan dan pengelolaan pengembangan pribadinya.

Bagi pembina asrama kualitas hakekat kehidupan asrama bukan sekedar pembentukan kebiasaan, namun juga suatu proses pembentukan nilai-nilai hidup sehingga kehadiran sekolah yang memiliki fasilitas asrama memberikan alternatif pendidikan yang terbebas dari polusi sosial yang melanda lingkungan kehidupan masyarakat seperti pergaulan bebas, narkoba, perkelahian antar pelajar, dan lain-lain. Pengelolaan pendidikan yang memiliki fasilitas asrama menjadi komprehensif secara life skill, soft skill, dan hard skill.

Berdasarkan penuturan anak yang tinggal di asrama merasa memiliki kualitas yang lebih dalam bidang akademik dari pada anak-anak yang hidup atau tinggal di luar asrama. Anak yang tinggal di asrama mendapat peningkatan dalam bidang akademik dan lebih kreatif. Berdasarkan hasil wawancara dengan anak-anak yang lebih suka tinggal di asrama menyadari bahwa tinggal di asrama lebih mandiri, bisa meningkatkan prestasi, dan dididik menjadi seorang yang hidup terbiasa dengan kedisiplinan. Bagi seorang anak asrama putri kualitas 
tinggal di asrama berbeda dengan anak-anak yang tinggal di luar atau kos selama menenmpuh pendidikan. Baginya mau tinggal di asrama karena di dalam lingkungan asrama itu banyak nilai positif yang didapatkan, seperti; disiplin belajar sudah dibuatkan jadwal, prestasi meningkat, bisa lebih mandiri, mendapatkan pengetahuan yang banyak tentang pendalaman iman (katekese, bina iman, rekoleksi, dll). Bagi seorang anak yang tinggal di asrama di Paroki Sekayam dan Entikong, mengatakan anak-anak yang tinggal di asrama banyak mendapat rengking tinggi di sekolah, bahkan dominan anak-anak yang tinggal di asrama mendapat juara dan berbagai prestasi di sekolah. Maka dilihat dari kualitas pendidikan Katolik yang memiliki fasilitas asrama masih mampu menjadi sarana dalam meningkatkan mutu pendidikan bagi putra/putri suku Dayak di wilayah perbatasan.

Berdasarkan hasil penelitian kurangnya peminat anak-anak untuk masuk ke asrama dikarenakan oleh beberapa faktor : munculnya Sekolah Negeri; munculnya sekolah negeri yang baru sangat besar pengaruhnya terhadap keberadaan penghuni asrama. Sekolah Negeri yang dibangun tersebut dekat dari rumah, biaya yang relatif lebih murah, dan gratis SPP. Faktor ekonomi orang tua; ekonomi yang dimiliki oleh orang tua berpengaruh bagi anak untuk tidak tinggal di asrama selama menempuh pendidikan. Hal tersebut nampak pada gaya hidup anak yang difasilitasi dengan kendaraan untuk berangkat sekolah dari rumah. Kemudahan-kemudahan tersebut anak tidak mau memilih asrama sebagai tempat tinggal. Sekolah Katolik yang memiliki fasilitas asrama bersaing semakin ketat dengan yayasan pendidikan lain dengan menawarkan fasilitas asrama yang hampir sama. Ketersediaan fasilitas sekolah dan asrama; anak kurang berminat tinggal di asrama dikarenakan fasilitas asrama tidak lengkap, misalnya persoalan wifi, alat-atat komunikasi yang tidak disediakan bahakan tidak diijinkan. Ketatnya tata tertib asrama; ketidakmampuan mematuhi kedisiplinan dan tidak tahan di dalam asrama menjadi seleksi alam. Anakanak ingin bebas, tidak mau dikekang dengan tata tertib yang ada di asrama, tidak bebas membawa handphone. Karakter peserta didik yang tidak suka terikat pada aturan yang dianggap membebani dan ingin bebas.

Kemajuan IPTEK; kemajuan IPTEK ini mempengaruhi gaya hidup anak yang terlalu asyik dengan alat komunikasi. Kebanyakan anak-anak tidak mau lepas dari handphone sedangkan di asrama anak-anak dilarang untuk membawa handphone. Banyaknya tawaran tempat tinggal (kost-kostan) atau tempat orang tua/saudara yang terjangkau dari lokasi sekolah. Anak-anak lebih memilih kost yang tidak terlalu terikat pada aturan yang dirasakan sulit. Biaya Sekolah Katolik yang memiliki fasilitas asrama relatif dianggap mahal.

Revitalisasi asrama merupakan bukti yang dapat menunjukan keterlibatan Gereja Katolik dalam mengembangkan pendidikan yang memiliki fasilitas asrama, seperti persekolahan Katolik di wilayah Nyarumkop yang sudah berusia satu abad lamanya, munculnya pengembangan Paroki di wilayah perbatasan yang juga menyediakan dan mengelola fasilitas asrama sebagai tempat tinggal bagi anak-anak Suku Dayak wilayah perbatasan. Oleh sebab itu, Gereja mengharapkan agar pengembangan sekolah katolik yang memiliki fasilitas asrama terus meningkatkan semangat persaudaraan yang menjadi salah satu ciri khas sekolah Katolik.

Seorang pembina asrama mengutarakan bahwa keterlibatan Gereja dalam merevitalisasi pengelolaan asrama untuk mengembangkan pendidikan bagi Suku Dayak di wilayah perbatasan Keuskupan Sanggau Kalimantan Barat untuk saat ini harus menjadi perhatian khusus. Tujuan revitalisasi pengelolaan asrama saat ini dilakukan untuk meningkatkan minat anak-anak yang diusia sekolah mau menempuh pendidikan dengan tinggal di asrama selama sekolah. Salah satu kekahsan pengelolaan pendidikan Katolik memiliki fasilitas asrama sebagai tempat untuk mengembangkan kemampuan kogniktif, apektif, dan pysikomotorik peserta didik.

Upaya merevitalisasi pengelolaan asrama dalam mengembangkan pendidikan bagi Suku Dayak di wilayah perbatasan Keuskupan Sanggau Kalimantan Barat Saat ini Indonesia sedang menggalakan konsep pendidikan berbasis karater. Sekolah swasta yang didirikan oleh Gereja dilengkapi dengan asrama, berarti Gereja berusaha untuk menyediakan tempat tinggal bagi anak-anak dan kaum muda yang berkeinginan uuntuk sekolah dengan jarak tempuh yang jauh. Konsep pendidikan swasta yang dilengkapi oleh fasilitas asrama memungkinkan usaha gereja mewartakan dan mencari kebenaran serta mengembangkan cinta kasih. Pendidikan yang dilengkapi dengan fasilitas asrama dapat meningkatkan kualitas dalam bidang pendidikan. Tapi juga memiliki toleransi, karakter, dan moral yang kuat.

Berdasarkan hasil wawancara dengan Bruder mengatakan revitalisasi asrama sangat penting mengingat asrama yang ada ini memang masih memegang desain lama. Seyogyanya model asrama dan cara pembinaannya pun harus mengikuti perkembangan jaman. Asrama yang usianya sudah cukup tua tersebut sangat membutuhkan 
sentuhan-sentuhan pihak donatur untuk mau berkerja sama mengelola asrama dari segi pendanaan. Lebih lanjut Bruder juga menekankan agar umat juga memiliki rasa untuk memperhatikan asrama yang sudah tua usianya dan mau meringankkan tanggannya untuk membantu perkembangan asrama, entah dari segi materil maupun moril.

Perhatian terhadap asrama memang sudah jauh berubah bila dibandingkan dengan jaman dulu. Asrama jaman dulu kalau masalah disiplin sangat kuat dan menghasilkan pendidikan yang berkualitas bagi banyak orang Dayak pedalaman. Anak-anak tidak mengeluh dididik dengan metode misi Gereja. Nilai-nilai disiplin yang menjadi prioritas sangat ditekankan.

Bagi para orang tua Suku Dayak yang di pelosok pedalaman dengan jarak antara rumah dan sekolah relatif jauh merasa kesulitan untuk mendapatkan sekolah anakanaknya, maka sekolah yang memiliki fasilitas asrama menjadi solusi. Untuk itu, Orang tua dari pedalaman cenderung menitipkan anak-anak mereka untuk dididik pada sekolah yang memiliki fasilitas asrama. Orang tua sadar bahwa sekolah Katolik yang memiliki asrama tidak hanya membantu anak untuk memiliki intelektual tinggi di sekolah, tapi juga dibina di asrama oleh para Pembina (Biarawan-Biarawati). Nilai yang ditanam pada sekolah yang memiliki fasilitas asrama seperti nilai hidup beriman Katolik, sikap toleransi, karakter, kebersamaan, etika, disiplin, mandiri, dan moral. Sekolah berfasilitas asrama sudah cukup banyak membantu dan mengantar putra-putri suku Dayak menjadi orang yang berpendidikan dan memandang pendidikan sebagai bagian dari hidup. Bahkan dalam kenyataan, asrama dapat menjadi jawaban atas kecemasan dan kebutuhan orang tua untuk menyekolahkan anak-anaknya. Orang tua berharap anaknya yang tinggal di asrama prestasinya rata-rata lebih unggul daripada anak-anak yang tinggal di kost-kostan atau tempat saudara/orang tua.

Berdasarkan hasil penelitian perkembangan zaman, kemajuan teknologi dan gaya hidup dalam berbagai bidang kehidupan sudah menggeser kualitas, kuantitas, dan pola persekolahan Katolik Swasta yang memiliki fasilitas asrama yang dianggap lama dan konvensional menuju pola baru yang dianggap moderat. Oleh karena itu, situasi asrama saat ini bagi seorang bruder jauh sekali perbedaan dari yang dulu. Sekarang anak-anak asrama sangat sulit untuk dididik menjadi anak yang disiplin, memiliki semangat kerja sama, gotong-royong dan lain sebagainya. Tuntutan anak-anak asrama sekarang mengarah pada gaya hidup yang bebas. Pola asrama yang menutut kedisplinan dirasa sebagai momok yang betulbetul menyiksa gaya hidup yang bebas di jaman sekarang. Oleh karena itu, tuntutan-tuntutan anak-anak asrama sangat lekat dengan situasi hidup jaman sekarang, seperti misalnya anak-anak diijinkan membawa HP, mengharapkan asrama menyediakan wifi, gaya hidup asrama yang penuh dengan fasilitas, tidak terlalu mengikat, dan lain sebagainya.

\section{SIMPULAN}

Hasil penelitain menunjukan kualitas dan kuantitas anak yang mau tinggal di asrama selama menempuh pendidikan semakin menurun. hal tersebut dipengaruhi oleh beberapa faktor, seperti Munculnya Sekolah Negeri, Faktor ekonomi orang tua, fasilitas asrama yang kurang, ketatnya tata tertib, banyaknya tawaran tempat tinggal seperti kos dan rumah keluarga, biaya asrama dan sekolah yang relative mahal, dan kemaujuan IPTEK. Oleh karena itu, Gereja perlu membuka diri untuk melakukan revitalisasi terhadap berbagai fasilitas asrama. Gereja bergerak cepat agar dapat merubah gaya hidup dan pola pikir anak-anak untuk tetap mencintai asrama sebagai tempat tinggal selama sekolah.

Gerakan revitalisasi asrama dapat dilakukan dengan mendesain asrama bergaya moderat dari sudut pandang bangunan tidak kelihatan kumuh, memiliki fasilitas teknologi yang canggih yang pada akhirnya membuat anak-anak bertahan tinggal di asrama selama sekolah. Mempertahankan metode pembinaan yang mengutamakan disiplin, kerja sama, gotong-royong, dan lain sebagainya.

\section{UCAPAN TERIMA KASIH}

Ucapan terima kasih disampaikan kepada lembaga Sekolah Tinggi Agama Katolik Negeri (STAKatN) Pontianak yang telah menyediakan dana dalam melakukan penelitian, kepada narasumber dan siapa saja yang terlibat dalam penelitian hingga terbitnya artikel di Jurnal ini.

\section{DAFTAR PUSTAKA}

Abisada Warstef. (2013). Pendidikan Model Asrama Yayasan Lokon St. Nikolaus. http://www.dionbata.com/2013/04/pendidikanmodel-asrama-yayasan-lokon.html diakses pada hari Jumat, 20 Juli 2018 Pukul 13.10.

Dewantara, J. A., Efriani, \& Afandi. (2020). Pemanfaatan Aplikasi Discord Sebagai Media Pembelajaran Online https://doi.org/10.24036/tip.v13i1.

Faridah, F., Arismunandar, A., \& Bernard, B. (2018). 
Sekolah Berasrama Di Sulawesi Selatan. Lentera Pendidikan : Jurnal Ilmu Tarbiyah Dan Keguruan, 21(2), 142. https://doi.org/10.24252/lp.2018v21n2i1

KWI, S. (1991). Kitab Hukum Kanonik (Codex Iuris Canonici). Obor.

Maslihah, S. (2011). Studi Tentang Hubungan Dukungan Sosial, Penyesuaian Sosial Di Lingkungan Sekolah Dan Prestasi Akademik Siswa Smpit Assyfa Boarding School Subang Jawa Barat. Jurnal Psikologi, 10(2), 103-114. https://doi.org/10.14710/jpu.10.2.103-114

Naili, Nuzulia, F., Hidayati, R., \& Setyawan, I. (n.d.). HUBUNGAN ANTARA PENYESUAIAN DIRI DENGAN PROKRASTINASI AKADEMIK SISWA SEKOLAH BERASRAMA SMP N 3 PETERONGAN JOMBANG Naili Zakiyah, Frieda Nuzulia Ratna Hidayati, Imam Setyawan.

Nugroho, A. (n.d.). "Mengintif Sekolah Islam Moderen Berasrama "; http://www.bbc.com/indonesia/laporan_khusus/2 011/08/110816_sekolahislam1.

Purnadi, F. S. (2015). Pendidikan Kkarakter dalam Sekolah Berasrama. FKIP Universitas Negeri Yogyakarta.

Putra, N. (2011). Metodologi Penelitian Kualitatif Pendidikan. RajaGrafindo Persada.

R. Hardawiryana (Trj.). (2002). Dokumen Konsili Vatikan II (Gravissimum Educationis). Obor.

Sholikhun. (2018). Pembentukan karakter siswa dengan sistem. Wahana Islamika: Jurnal Studi Keislaman, 4(1), 48-64.

Suci, N. W. (2017). Penyesuaian Diri Anak Di Sekolah Berasrama.

Susiyani, A. S. (n.d.). Manajemen Boarding School dan Relevansinya dengan Tujuan Pendidikan Islam di Muhammadiyah Boarding School ( MBS ) Yogyakarta. 2(November 2017), 327-347.

Widyastuti, A. D. atmi. (n.d.). "Mencermati Ciri Khas Pendidikan Katolik; oleh Sr. Avriana Dwi atmi Widyastuti, $C B$.

http://www.sesawi.net/mencermati-cirikhaspendidikan-katolik/ diakses pada 10 Juli 2018 Pukul 13.00.

Wikipedia. (n.d.-a). https://id.wikipedia.org/wiki/Gereja_Katolik_Ro ma, diakses pada 18 Juli 2018, pukul 09.20.

Wikipedia. (n.d.-b). https://id.wikipedia.org/wiki/SMA_Seminari_Sant o_Paulus_Nyarumkop diakses pada 10 Juli 2018 pukul 13.50.

Winata, D. K. (n.d.). http://mediaindonesia.com/read/detail/133818guru-jadi-panutan-pendidikan-karakter diakses pada 5 Juli 2018 Pukul 13.30.

www.atmajaya.ac.id. (n.d.). Evaluasi 100 Tahun
Persekolahan Katolik Nyarumkop di Keuskupan Agung Pontianak Kalimantan Barat, https://www.atmajaya.ac.id/web/KontenUnit.aspx ?gid=penelitian-

pendidikan\&ou $=$ pkpm\&cid=Evaluasi Persekolahan-Katolik-Nyarumkop diakes pada 10 Juli 2018. 